\title{
Efficacy of crizotinib therapy for a patient with non-small cell lung cancer with ALK gene rearrangement - case report and review of current therapeutic options
}

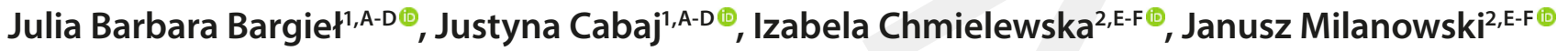 \\ ${ }^{1}$ Medical University, Lublin, Poland \\ ${ }^{2}$ Department of Pneumonology, Oncology and Allergology, Medical University, Lublin, Poland \\ A - Research concept and design, B - Collection and/or assembly of data, C - Data analysis and interpretation, \\ $D$ - Writing the article, E-Critical revision of the article, F- Final approval of the article
} Bargieł JB, Cabaj J, Chmielewska I, Milanowski J. Efficacy of crizotinib therapy for a patient with non-small cell lung cancer with ALK gene
rearrangement - case report and review of current therapeutic options. J Pre-Clin Clin Res. doi: 10.26444/jpccr/141598

\begin{abstract}
I Abstract
Introduction. Currently, nearly 23,000 cases of lung cancer are diagnosed in Poland annually, of which $5 \%$ are cases with rearrangements in the ALK gene. In recent years, tremendous progress has been made in understanding the genetic makeup of this type of cancer, which has enabled the use of new therapies, in particular, molecularly targeted drugs. Crizotinib is the first oral small molecule inhibitor of ALK, MET and ROS1 receptor tyrosine Kinases approved by the European Medicines Agency(EMA).

Case report. The paper presents the case of a 62-year-old patient diagnosed with non-small cell lung cancer with rearrangement in the ALK gene in stage IV of the disease. The patient was qualified for treatment with crizotinib under the B6 drug programme. Treatment started in May 2019. During treatment, assessment was made at 3 control points, where the first and second showed a partial response according to the RECIST $1.1 \mathrm{scale}$; in the next assessment, the response was maintained in the form of disease stabilization.
\end{abstract}

\section{Key words}

lung cancer, crizotinib, tyrosine kinase inhibitors, ALK gene rearrangement

\section{INTRODUCTION}

Lung cancer is responsible for as many as 1.6 million deaths annually [1]. It is the second most frequently diagnosed cancer and the leading cause of cancer deaths in 2020. One in ten cancers are diagnosed and one in five deaths are due to lung cancer. The five-year survival rate of lung cancer patients is only $10 \%-\mathrm{o} 20 \%[2]$. The high mortality rate is related to the fact that many tumours are already advanced at diagnosis. Studies have shown that at the time of diagnosis, $43.7 \%$ of patients had metastases to distant organs [3].

The most common histological subtype of lung cancer is non-small cell (NSCLC) (about 85\%), in which the most common are lung adenocarcinoma and squamous cell carcinoma [4]. While the small-cell type (15\%) is more aggressive, inoperable, even with a good response to treatment, in most cases the disease relapses rapidly. The non-small cell type often has a better prognosis [5].

The etiology of lung cancer is most often associated with smoking. This relationship is most strongly expressed in squamous and small cell carcinoma. Adenocarcinoma is more common among non-smokers $[1,4]$. Significant links have been found between family history of lung cancer and its risk of developing [6]. Studies have shown that about $8 \%$ of all lung cancer cases result from genetic predisposition, and having a first-degree relative with confirmed lung cancer increases the risk of lung cancer development by $50 \%$ [7].

Adress for correspondence: Julia Barbara Bargieł, Medical University, Lublin, Poland E-mail: Juliabargiel@interia.pl

Received: 25.05.2021; accepted: 25.08.2021; first published: 03.09.2021
Interestingly, the picture of the lung cancer genome is clearly different between never-smokers and smokers. There is a much higher frequency of somatic mutations, mainly cytosine to adenine transversion and KRAS and TP53 mutations, in smokers. On the other hand, never-smokers usually have cytosine to adenine conversion resulting in more frequent EGFR mutations and translocations activating ROS1 and ALK. The identification of gene changes has significantly changed the management of lung cancer patients. Based on the results of tumour genotyping, individualized therapy with matched tyrosine kinase inhibitors can be adapted [4]. The study of disorders in the epidermal growth factor receptor gene and rearrangement of the anaplastic lymphoma kinase gene is now considered routine [8].

Treatment for lung cancer has changed significantly. Initially, it was limited to cytotoxic chemotherapy - platinum compounds related to the third-generation cytotoxic drugs paclitaxel, gemcitabine and pemetrexed [1]. Today, the action of chemotherapeutic agents is based on blocking the cell cycle. Recent advances in cancer treatment include the development of targeted therapies that block specific molecules whose over-expression or increased activity occurs only in neoplastic cells [1].

As many as 538 kinases are coded in the human genome. These are enzymes that regulate key cell functions by transferring $\gamma$-phosphate from the ATP cofactor to various substrates. In turn, the appropriate phosphatases reverse their action. Kinases play an important role in signaling pathways that regulate the processes taking place in neoplastic cells [9]. With their over-expression or increased 
activity, carcinogenesis occurs. Most protein kinases promote cell proliferation, survival and migration. Understanding these mechanisms has led to the use of kinase inhibitors as targeted therapeutic strategies in the treatment of human malignancies. Currently, there are approximately 35 drugs available, including 31 for anti-cancer therapy, approved by the US Food and Drug Administration (FDA) [10]. Development of new compounds is ongoing, many new molecules have entered clinical trials and others are at the pre-clinical stage. Kinase inhibitors represent a new and promising approach to cancer therapy that provides beneficial clinical effects [11].

One of the tyrosine kinase inhibitors (TKI) is crizotinib, which targets ALK, ROS1 and MET receptor kinases [12]. It was first approved by the FDA in 2011 for the standard treatment of ALK-positive NSCLC [13]. Crizotinib is more effective than standard chemotherapy in patients with previously treated advanced non-small cell lung cancer with ALK rearrangement. Anaplastic lymphoma kinase (ALK) is a tyrosine kinase target also in other cancers, including anaplastic large cell lymphoma and neuroblastoma. Compared to standard chemotherapy, crizotinib therapy results in a longer progression-free survival, a significantly higher response rate, reduction in symptoms, and a significant improvement in the overall quality of life [14].

Several randomized studies have shown that therapy with the second-generation ALK inhibitors, alectinib, brigatinib and ensartinib, results in better clinical effects compared to crizotinib [15-19].

The use of tyrosine kinase inhibitors has obtained unprecedented benefits in terms of survival in selected patients. However, overall cure rates for survival in NSCLC remain low, particularly in metastatic disease. Therefore, further research into new drugs and combination therapies is necessary, to prolong survival and increase the possibility of cure in a number of patients [4].

This study describes the case of a patient treated with crizotinib in connection with the diagnosis of non-small cell lung cancer with ALK gene rearrangement.

\section{CASE REPORT}

A 61-year-old mlen was admitted to the Pulmonology Clinic in 2019 due to a persistent cough that had lasted for two months. Advanced diagnostics were started with a bronchofiberoscopy in which balloting granulation tissue was observed in the bronchus to the lower left lobe of the left lung, $7 \times 5.5 \mathrm{~cm}$ in size. A slice was taken from the lesion for histopathological evaluation, which showed the presence of non-small cell glandular carcinoma of the left lung with ALK gene rearrangement. Computed tomography revealed an osteosclerotic remodeling of Th10 and the left sacrum, most likely of a metastatic nature. The image of the brain and abdominal cavity in computed tomography did not raise any concerns. Stage IV was established. The general condition of the patient, determined on the basis of the 6-point Eastern Cooperative Oncology Group (ECOG) scale, was satisfactory and remained at the level of 1 . The patient did not report any pain. Treated comorbidities (hypertension, type 2 diabetes, obesity), was stable and did not present any contraindications for treatment initiation.

From 2016, a programme for the treatment of non-small cell lung cancer with crizotinib, refunded by the National
Table 1. Criteria for patient inclusion in the refunded Xalkori treatment programme [31]

CRITERIA FOR PATIENT INCLUSION IN THE REFUNDED XALKORI TREATMENT PROGRAM

1 histological or cytological diagnosis of lung adenocarcinoma or non-small cell lung cancer with predominance of adenocarcinoma

2 diagnosis of said neoplasm at the stage of local advancement or generalization

3 presence of rearrangement in the ALK gene based on fluorescent in situ hybridization (FISH) or next generation sequencing (NGS) using a validated test

4 progression after first-line chemotherapy after previous systemic treatment (multi-drug chemotherapy with platinum or monotherapy)

5 presence of measurable changes to objectively assess the response in imaging tests using the RECIST 1.1 evaluation criteria or the presence of quantifiable changes that are not measurable

6 no metastases in the central nervous system or signs of progression of metastases in the central nervous system in patients after previous local treatment (surgery or radiotherapy) and no clinically significant neurological symptoms and the need to increase the dose of glucocorticosteroids in the last month prior to enrollment in the program

7 resolution or reduction to grade 1 of adverse reactions related to previous treatment (exception - hair loss)

8 age over 18

9 0-2 degree efficiency according to the Zubrod-WHO or ECOG classification

10 exclusion of coexistence of clinically significant diseases (uncontrolled arterial hypertension, unstable coronary artery disease, myocardial infarction in the last year, ventricular arrhythmias requiring treatment)

11 the activity of the hematopoietic system enabling treatment in accordance with the current Summary of Product Characteristics

12 treatable kidney function (creatinine levels up to 1.5 times upper limit of normal)

13 hepatic function enabling treatment (bilirubin levels not exceeding 1.5 times the upper limit of normal and the activity of transaminases and alkaline phosphatase not exceeding 5 times the upper limit of normal)

14 absence of contraindications to the use of crizotinib specified in the Summary of Product Characteristics

15 exclusion of the simultaneous use of chemotherapy and other molecularly targeted drugs

Health Fund, has been approved for use, for which the patient must meet all the criteria listed in Table 1. After assessing the patient's condition, it was found that he patient met the above-mentioned requirements; therefore, in May 2019, therapy with a molecularly targeted drug was started - crizotinib (Xalkori 2x250 mg per day). Additionally, due to the identified osteolytic changes in the skeletal system, bisphosphonate therapy was started.

At the first check-up in August 2019, a chest CT scan showed a reduction in tumour volume, showing a partial response to treatment (Fig. 1). RECEIST 1.1 was used to objectively assess the patient's response to Xalkori. (CR -

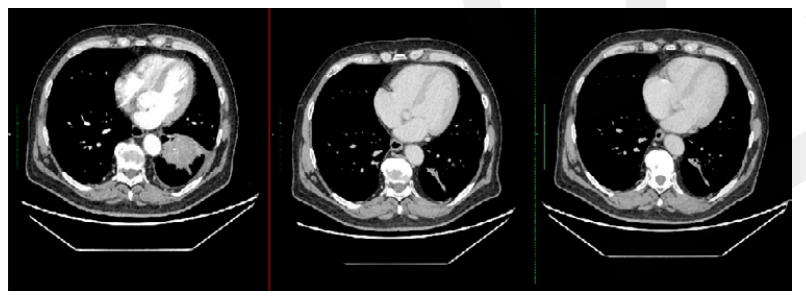

Figure 1. Comparison of CT images of the chest in which remission of neoplastic lesions is observed (from the left, May 2019, August 2019, August 2020 own study) 
complete response, PD - disease progression, PR - partial response, $\mathrm{SD}$ - disease stabilization) [20]. The patient's fitness level was 1 on the ECOG scale. Subsequent imaging studies confirmed the persistence of partial regression. No new metastatic lesions were detected. During treatment, after about two weeks of taking the drug, swelling of the lower limbs appeared, which is a common side-effect of crizotinib. Low doses of diuretics were used; however, trace swelling persisted during treatment.

Due to the previously mentioned side-effects of the biological drug therapy, and in particular the high risk of hepatotoxicity, the level of the liver enzymes AST and ALT was strictly monitored in the patient for fear of liver damage. Measurements were performed systematically (every 2 months), which allowed for quick detection of the elevation of transaminase values one year after the initiation of crizotinib therapy. Protective treatment was implemented, noting an improvement in liver parameters. Currently, the level of liver enzymes is satisfactory, remaining within reference standards (Fig. 2).

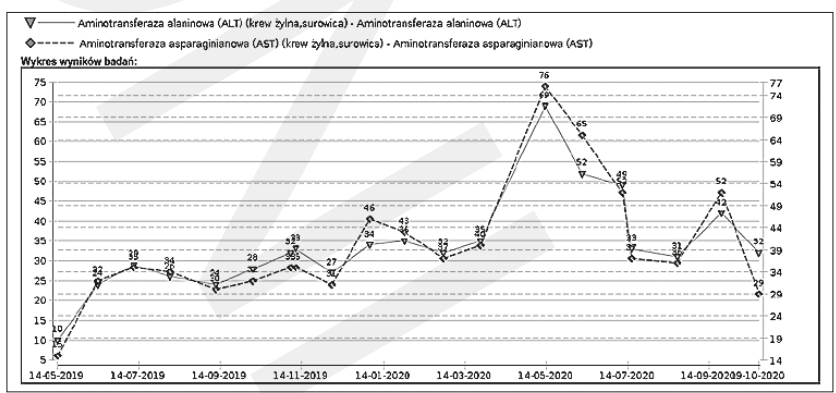

Figure 2. Graphical presentation of the results of liver enzyme test over the entire treatment period - own elaboration

\section{DISCUSSION}

The above case report is an example of the effectiveness of molecularly targeted therapy. Rapid response to treatment with crizotinib in the form of partial regression and the absence of serious side-effects enable the long-term use of tyrosine kinase inhibitors. In the diagnosis and treatment planning, it is necessary to take into account assessment of the predictive markers, such as rearrangements in the ALK gene. Decisions regarding the choice of treatment in the first line should be made individually. The results of registration tests, the possibility of sequential treatment and the availability of reimbursement in Poland should be taken into account. Median PFS is presented in Table 2. In the case of the presented patient, at the time of initiation of treatment, crizotinib was the only reimbursed option. The patient responded to treatment and partial regression continues with an acceptable level of side- effects. In the event of progression, we have several drugs at our disposal that have shown effectiveness after first-line treatment with crizotinib. Some of them also showed better effectiveness in the first-line treatment compared to crizotinib.

Recent studies conducted in 2020 indicate the high effectiveness of alectinib. This antibody shows a great advantage over other drugs from the discussed group in the treatment of patients both with and without CNS metastases, previously not treated with ALK inhibitors. PFS data showed a significantly prolonged PFS with alectinib [hazard ratio (HR)
Table 2. Median PFS based on registration studies of ALK tyrosine kinase inhibitors

\begin{tabular}{lcc}
\hline Drug & Studies & PFS \\
\hline Crizotinib & Profile 1014 & 10.9 \\
\hline Ceritinib & ASCEND 4 (I line) & 16.6 \\
\hline Ceritinib & ASCEND 5 (II line) & 5.4 \\
\hline Alectinib & ALEX (I line) & 34.8 \\
\hline Alectinib & ALUR (III line) & 9.6 \\
\hline Brygatinib & ALTA -1 (I line) & 24 \\
\hline Lorlatinib & CROWN (I line) & 18.3 \\
\hline
\end{tabular}

0.43, 95\% confidence interval (CI) 0.32-0.58; median PFS 34, 8 months versus 10.9 months with crizotinib]. An OS benefit of alectinib was observed in patients with central nervous system metastases at study entry. A significant clinical benefit was also demonstrated by a 2018 study, which confirmed the higher effectiveness of alectinib treatment compared to chemotherapy after progression during crizotinib treatment. The percentage of objective responses to alectinib was significantly higher (over 54\% advantage), and comparing the occurrence of sideeffects (alectinib - 27\%, chemotherapy - 42\%), the biological drug in question has a much safer profile [21].

Lorlatinib is a new third-generation molecular drug approved in May 2019. Its innovative feature is the ability to cross the blood-brain barrier [22]; therefore, it is a highly effective agent in the treatment of CNS metastases [23-25]. In addition, lorlatinib inhibits ALK more strongly than the first and second generation inhibitor, and maintains its effectiveness in all known single mutations causing ALK resistance [26]. In an analysis of the results among patients with previously untreated advanced ALK positive NSCLC, those who received lorlatinib had a significantly longer progression-free survival compared to those who received crizotinib [27]. The incidence of grade 3 or 4 adverse reactions was higher with lorlatinib due to the frequent occurrence of lipid disorders: hypercholesterolaemia and hypertriglyceridaemia [22].

Brigatinib is a drug which, despite belonging to the older generation of molecular drugs, is highly effective regardless of the type of therapy used previously. In a randomized, phase III study of 275 patients; 137 were assigned to brigatinib and 138 to crizotinib. The progression-free survival rate was higher with brigatinib than with crizotinib. With a median follow-up of 24.9 months for brigatinib, brigatinib showed a consistent advantage in PFS compared to crizotinib (hazard ratio [HR], 0.49 [95\% CI, 0.35 to 0.68 ]; log-rank $\mathrm{P}<.0001$; median, $24.0 \mathrm{v} 11.0$ months). Patients who started treatment with brigatinib showed a very good tolerance to the drug with side-effects reported by only $0.7 \%[28,29]$.

Ceritinib is a new, reimbursed drug, a progression from crizotinib. Ceritinib, a second-generation ALK inhibitor, has been evaluated in the ASCEND clinical trial series, in which the ASCEND-5 study compared the efficacy and safety of ceritinib with chemotherapy in patients with stage IIIB / IV NSCLC and the presence of ALK gene rearrangement after progression on first-line systemic therapy (crizotinib or platinum doublet). The study included 231 patients who were randomized 1:1 with ceritinib $750 \mathrm{mg}$ once daily to an arm on an empty stomach, with pemetrexed $500 \mathrm{mg} / \mathrm{m} 2$ or docetaxel $75 \mathrm{mg} / \mathrm{m} 2$ intravenously or to an arm every 3 weeks. The primary endpoint in this study was PFS. 
In the current study, there was a statistically significant prolongation of the median PFS in patients treated with ceritinib, compared to the group treated with chemotherapy (5.4 vs. 1.6 months; $\mathrm{HR}=0.49 ; 95 \%$ CI: $0.36-0.67 ; \mathrm{p}<0.0001$ ). The ORR was 39.1 and $6.9 \%$, respectively, for the above groups [30]. No randomized trial has been conducted so far to directly compare the results of treatment with ceritinib and crizotinib. However, the ASCEND 4 study showed that ceritinib was more effective than first-line chemotherapy. The study showed that the use of ceritinib reduces the risk of progression or death by $45 \%$ ( $\mathrm{HR}=0.55 ; 95 \% \mathrm{CI}$ : $0.42-0.73 ; \mathrm{p}<0.00001)$. The median PFS for patients treated with ceritinib was 16.6 months, and 8.1 months for patients receiving chemotherapy. Patients treated with ceritinib had a significantly higher ORR compared to patients receiving chemotherapy (72.5 vs. $26.7 \%$ ) [30].

Currently, molecularly targeted drugs represent a great potential in the therapy of many disease entities. Particular progress has been made in terms of prolonged survival in patients with NSCLC; hence, it is important to identify its genetic makeup when determining the histopathological affiliation of a tumour. This action will allow careful selection of a specific inhibitor of a given receptor, thus increasing the chances of successful treatment.

In summary, patients diagnosed with non-small cell lung cancer with ALK gene rearrangement can benefit from the use of a biological drug. It has been shown that molecular targeting has advantages in terms of progression-free survival and overall survival. When ALK has been treated with other systemic treatments, such as chemotherapy, it is acceptable to complete the treatment. It is important that a patient with known ALK rearrangement receives an ALK inhibitor at some point during treatment, and that the most effective treatment should be given first.

\section{REFERENCES}

1. De Mello RA, Neves NM, Tadokoro H, et al. New Target Therapies in Advanced Non-Small Cell Lung Cancer: A Review of the Literature and Future Perspectives. J Clin Med. 2020; 9(11): 3543. https://doi. org $/ 10.3390 / \mathrm{jcm} 9113543$

2.Sung H, Ferlay J, Siegel RL, et al. Global Cancer Statistics 2020: GLOBOCAN Estimates of Incidence and Mortality Worldwide for 36 Cancers in 185 Countries. CA Cancer J Clin. 2020; 71(3):209-249. https://doi.org/10.3322/caac.21660

3. Tamura T, Kurishima K, Nakazawa K, et al. Specific organ metastases and survival in metastatic non-small-cell lung cancer. Mol Clin Oncol. 2014; 3: 217-221. https://doi.org/10.3892/mco.2014.410

4. Herbst R, Morgensztern D, Boshoff C. The biology and management of non-small cell lung cancer. Nature. 2018; 553: 446-454. https://doi. org/10.1038/nature25183

5. Vuong HG, Nguyen TQ, Nguyen HC, et al. Efficacy and Safety of Crizotinib in the Treatment of Advanced Non-Small-Cell Lung Cancer with ROS1 Rearrangement or MET Alteration: A Systematic Review and Meta-Analysis. Targ Oncol. 2020; 15: 589-598. https://doi.org/10.1007/ s11523-020-00745-7

6. Ang L, Chan CPY, Yau WP, et al. Association between family history of lung cancer and lung cancer risk: a systematic review and metaanalysis. Lung Cancer. 2020; 148: 129-137. https://doi.org/10.1016/j. lungcan.2020.08.012

7. Kanwal M, Ding XJ, Cao Y. Familial risk for lung cancer. Oncol Lett. 2017; 13(2): 535-542. https://doi.org/10.3892/ol.2016.5518

8. Kris MG, Johnson BE, Berry LD, et al. Using multiplexed assays of oncogenic drivers in lung cancers to select targeted drugs. JAMA. 2014; 311(19): 1998-2006. https://doi.org/10.1001/jama.2014.3741

9. Fabbro D, Cowan-Jacob SW, Moebitz H, et al. Ten things you should know about protein kinases: IUPHAR Review 14. Br J Pharmacol. 2015; 172(11): 2675-700. https://doi.org/10.1111/bph.13096

10. Bhullar KS, Lagarón NO, McGowan EM, et al. Kinase-targeted cancer therapies: progress, challenges and future directions. Mol Cancer. 2018; 19;17(1): 48. https://doi.org/10.1186/s12943-018-0804-2
11. Shah DR, Shah RR, Morganroth J, et al. Tyrosine kinase inhibitors: their on-target toxicities as potential indicators of efficacy. Drug Saf. 2013; 36(6): 413-26. https://doi.org/10.1007/s40264-013-0050-x

12. Shaw AT, Riely GJ, Bang YJ, et al. Crizotinib in ROS1-rearranged advanced non-small-cell lung cancer (NSCLC): updated results, including overall survival, from PROFILE 1001. Ann Oncol. 2019; 30(7): 1121-1126. https://doi.org/10.1093/annonc/mdz131

13. Hoang T, Myung S-K, Pham TT, et al. Efficacy of Crizotinib, Ceritinib, and Alectinib in ALK-Positive Non-Small Cell Lung Cancer Treatment: A Meta-Analysis of Clinical Trials. Cancers. 2020; 12(3): 526. https:// doi.org/10.3390/cancers12030526

14. Shaw AT, Kim DW, Nakagawa K, et al. Crizotinib versus chemotherapy in advanced ALK-positive lung cancer. N Engl J Med. 2013; 368(25): 2385-94. https://doi.org/10.1056/NEJMoa1214886

15. Peters S, Camidge DR, Shaw AT, et al. ALEX Trial Investigators. Alectinib versus Crizotinib in Untreated ALK-Positive Non-SmallCell Lung Cancer. N Engl J Med. 2017; 377(9): 829-838. https://doi. org/10.1056/NEJMoa1704795

16. Camidge DR, Kim HR, Ahn MJ, et al. Brigatinib versus Crizotinib in ALK-Positive Non-Small-Cell Lung Cancer. N Engl J Med. 2018; 379(21): 2027-2039. https://doi.org/10.1056/NEJMoa1810171

17. Selvaggi G, Wakelee HA, Mok T, et al. Phase III randomized study of ensartinib vs crizotinib in anaplastic lymphoma kinase (ALK) positive NSCLC patients: EXALT3. Presented at the International Association for the Study of Lung Cancer World Conference on Lung Cancer, Singapore, August 8, 2020.

18. Camidge DR, Dziadziuszko R, Peters S, et al. Updated efficacy and safety data and impact of the EML4-ALK fusion variant on the efficacy of alectinib in untreated ALK-positive advanced non-small cell lung cancer in the global Phase III ALEX Study. J Thorac Oncol. 2019; 14: 1233-1243. https://doi.org/10.1016/j.jtho.2019.03.007

19. Camidge DR, Kim HR, Ahn M-J, et al. Brigatinib versus crizotinib in advanced ALK inhibitor-naive ALK-positive non-small cell lung cancer: second interim analysis of the Phase III ALTA-1L trial. J Clin Oncol. 2020; 1; 38(31): 3592-3603. https://doi.org/10.1200/jco.20.00505

20. Płużański A. Kryteria oceny odpowiedzi na leczenie RECEIST 1.1. Nowotwory. J Oncol. 2014; 64(4): 331-335. https://doi.org/10.5603/ NJO.2014.0055

21. Novello S, Mazières J, Oh I-J, et al. Alectinib versus chemotherapy in crizotinib-pretreated anaplastic lymphoma kinase (ALK)-positive non-small-cell lung cancer: results from the phase III ALUR study. Ann Oncol. 2018; 29(6): 1409-1416. http://doi: 10.1093/annonc/mdy121

22. Shaw AT, Bauer TM, de Marinis F, et al. CROWN Trial Investigators. First-Line Lorlatinib or Crizotinib in Advanced ALK-Positive Lung Cancer. N Engl J Med. 2020; 383(21): 2018-2029. https://doi.org/10.1056/ NEJMoa2027187

23. Zou HY, Friboulet L, Kodack DP, et al. PF-06463922, an ALK/ROS1 inhibitor, overcomes resistance to first and second generation ALK inhibitors in preclinical models. Cancer Cell. 2015; 28: 70-81. https:// doi.org/10.1016/j.ccell.2015.05.010

24. Horn L, Whisenant JG, Wakelee H, et al. Monitoring therapeutic response and resistance: analysis of circulating tumor DNA in patients with ALK+ lung cancer. J Thorac Oncol. 2019; 14: 1901-1911. https:// doi.org/10.1016/j.jtho.2019.08.003

25. Johnson TW, Richardson PF, Bailey S, et al. Discovery of (10R)-7amino-12-fluoro-2,10,16-trimethyl-15-oxo-10,15,16,17-tetrahydro- $2 \mathrm{H}$ 8,4-(metheno)pyrazolo[4,3-h][2,5,11]-benzoxadiazacyclotetradecine3 -carbonitrile (PF-06463922), a macrocyclic inhibitor of anaplastic lymphoma kinase (ALK) and c-ros oncogene 1 (ROS1) with preclinical brain exposure and broad-spectrum potency against ALK-resistant mutations. J Med Chem. 2014; 57: 4720-4744. https://doi.org/10.1021/ jm500261q

26. Gainor JF, Dardaei L, Yoda S, et al. Molecular mechanisms of resistance to first- and second-generation ALK inhibitors in ALK-rearranged lung cancer. Cancer Discov. 2016; 6: 1118-1133. https://doi.org/10.1158/21598290

27. Solomon B, Beauer TM, Marinis De F, et al. Lorlatinib vs Crizotinib in the First-line Treatment of Patients (pts) with Advanced ALK-Positive Non-Small Cell Lung Cancer (NSCLC): Results of the Phase 3 CROWN Study. Ann Oncology. 2020; 31(4): 1180-1181. https://doi.org/10.1016/j. annonc.2020.08.2282

28. Lin M.H, Pan X, Hou P, et al. Real-world treatment duration in ALKpositive non-small-cell lung cancer patients receiving brigatinib through the early access program. Future Oncol. 2020; 16(15): 1031-1041. http:// doi: 10.2217/fon-2019-0849

29. Camidge DR, Kim HR, Ahn MJ, et al. Brigatinib Versus Crizotinib in Advanced ALK Inhibitor-Naive ALK-Positive Non-Small Cell Lung Cancer: Second Interim Analysis of the Phase III ALTA-1L Trial. J Clin Oncol. 2020; 1; 38(31): 3592-3603. https://doi: 10.1200/JCO.20.00505

30. Shaw AT, Kim TM, Crinò L, et al. Ceritinib versus chemotherapy in patients with ALK-rearranged non-small-cell lung cancer previously given chemo-therapy and crizotinib (ASCEND-5): a randomized, controlled, open-label, phase 3 trial. Lancet Oncol. 2017; 18(7): 874-886. https://doi.org/10.1016/S1470-2045(17)30339-X

31.Załacznik B.6. Leczenie niedrobnokomórkowego raka płuca https:// www.gov.pl/web/zdrowie/choroby-onkologiczne 